RUTTER, M. (1987) Temperament, personality and personality disorder. British Journal of Psychiatry, 150, 443-458.

Stevenson, J. E. \& GrahaM, P. J. (1982) Temperament: a consideration of concepts and methods. In Temperamental Differences in Infants and Young Children. Ciba Foundation Symposium 89 (eds R. Porter and G. M. Collins). London: Pitman.

\section{Huntington's Chorea}

SIR: Martindale (Journal, March 1987, 150, 319-323) has raised an important issue that is relevant not only to Huntington's chorea but also to child psychiatry. It is well known that parents often have difficulty in recognising depression in their children. Professional responses to child psychiatric difficulties are less often discussed, and it seems worth drawing attention to a suggestion recently put forward by Emde $e t$ al (1986). Childhood depression was described many years ago, but it took a long time to gain general acceptance both by clinicians and by research workers. Emde et al hypothesised that this might be because depressed children threaten to arouse painful feelings in the professionals with whom they come into contact, and this may lead the professionals to fail to recognise the condition.

We are all familiar with 'observer effects' in research and these often seem to be regarded as contaminations which prevent us from discerning the truth. Both Martindale and Emde et al seem to suggest that this is only partially true and that some emotional responses (such as denial) will blind us to the truth, but others, such as the ability to tolerate feelings of hopelessness, helplessness and sadness in ourselves, may enable us to make a diagnosis which would otherwise elude us.

If this is correct it would seem to have several implications. Firstly, regarding teaching, perhaps we should spend more time helping our trainees to be more aware of their emotional responses to their patients; and secondly, as regards research, it would at least seem worth recording the emotional reactions of the interviewer to the patient.

My clinical impression is that patients often evoke similar emotional responses in a large number of professionals, and it could be that we should be taking more notice of this.

Department of Child and Family Psychiatry St Thomas' Hospital, London SE1 7EH

\section{Roference}

Emde, R. N., Harman, R. J. \& GoOd, W. V. (1986) Depressive feelings in children: a transactional model for research. In Depression in Young People, Developmental and Clinical Perspectives (eds M. Rutter, C. E. Izard and P. B. Read). New York \& London: The Guilford Press.

\section{Anorexia and Antidepressants}

SIR: We wish to take up and extend Crisp's theme (Journal, March 1987, 150, 355-358) regarding the mode of action of antidepressant drugs in patients with anorexia nervosa. We have recently studied a group of four male patients with eating disorder, depressive symptoms, and obsessional behaviour.

All four have several features in common, including early age of onset (13-15 years), dietary restriction with consequent weight loss, and obsessional, repetitive exercise routines. One patient exercises with such force that he has sustained several muscle injuries. Three of the patients have been admitted to hospital in the past with transient weight gain. All patients have experienced marked anxiety in relation to loss of control of body weight. This has occurred, for example, when exercise was disrupted by injury or infection, and has led to anticipatory ruminations about the risk of contracting illness and losing control over body weight or body 'fat content'.

In all four, obsessional behaviour has extended beyond the spheres of diet, preparation of food, and preoccupation with exercise to the extent that they are unable to make simple decisions-almost amounting to 'folie de doute'. Three of the four patients are high-achievers academically, pursuing courses in tertiary education; the fourth has been sufficiently ill to interrupt his schooling, although he was regarded premorbidly as being of above average potential. Their academic success has been jeopardised by their obsessional insistence on studying every subject in excessive detail, which leads to their falling behind in their study schedules, causing anxiety and precipitating further ruminations.

All four are currently improved in their academic and social functioning (but not in their core anorexic psychopathology) following the administration of drugs which block 5HT re-uptake with varying degrees of specificity (e.g. fluvoxamine or clomipramine).

Crisp justifies the use of clomipramine by drawing attention to the possible primary phobic and secondary avoidance behaviour and obsessional features within anorexia nervosa. We concur with the view that in some anorexic patients obsessional features play an important role (Dally, 1969), particularly in male patients (Beumont, 1972), and such symptoms contributed significantly to the difficulties encountered by our patients. Taking Crisp's argument that tricyclic drugs have an immediate effect on drive behaviour further, we suggest that in addition they reduce repetitive, 'stereotyped' behaviour as manifested in impaired decision-making seen in these patients. 
It is likely (Dally, 1969) that many such patients do not seek, or even actively avoid, in-patient treatment and in these circumstances the prescription of 5HT re-uptake blocking drugs may prove to be of considerable value in their academic and social functioning, although not in their core anorexic psychopathology.

I. REID

K. P. EBMEIER

J. A. O. BESSON

Department of Mental Health

G. W. AsHCROFT

University of Aberdeen

Aberdeen AB9 2ZD

\section{Roferences}

Dally, P. (1969) Anorexia Nervosa. London: Heinemann.

Beumont, P. J. V., BeARDWOOd, C. J. \& RusselL, G. F. M. (1979)

The occurrence of the syndrome of anorexia nervosa in male subjects. Psychological Medicine, 2, 216-231.

\section{Zinc in Senile Dementia}

SiR: McLoughlin (Journal, March 1987, 150, 409) appears to have selected information from various studies quoted by Srinivasan (1984) and concluded that lower zinc levels are present in the elderly functionally ill and in those with confusion. These studies cover a wide range of diagnoses and relate both to adult and psychogeriatric populations.

Our paper clearly describes the work of Bunker $e t$ al (1984), who suggest that the mean level of plasma zinc in healthy elderly adults is $11 \mu \mathrm{mol} /$ litre (s.d. = 1.2). The levels reported in our study compare well with Bunker's elderly group. It is reasonable, therefore, to imply that the low levels of zinc in senile dementia which McLoughlin suggests he would have demonstrated using a healthy elderly control group would not have materialised.

\section{Lynfield Mount Hospital Heights Lane \\ Bradford BD9 6DP}

Chris KeNN ELIzABETH GibB

\section{References}

Sennivasan, D. P. (1984) Trace elements in psychiatric illness. British Journal of Hospital Medicine, 32, 77-79.

BUNKER, V. W., HDNKS, L. J., LAWSON, M. S. \& CLAYTON, B. E. (1984) Assessment of zinc and copper status of healthy elderly people using metabolic balance studies and the measurement of leucocyte concentrations. American Journal of Clinical Nutrition, 10, 1096-1102.

\section{Life Events and Mania}

SIR: We are surprised that the Journal published an article which purports to measure life events prior to the onset of mania (Journal, February 1987, 150, 235-240) when the method of life event assessment is simply that of searching case notes. Ambelas makes some important deductions from his assessment of life events, but we believe that the weakness of the life event assessment method is such that these could be misleading.

We are in the early stages of measuring life events prior to the onset of mania and are using the reliable method of Brown \& Harris (1978) (LEDS). After assessment of only 11 patients two factors have become clear. Firstly, in the year prior to onset of mania 26 life events (according to the LEDS) have been elicited at interview, but only two of these were recorded in case notes. Secondly, the time between onset of symptoms and admission varied between 2 and 90 days (median 13 days), which indicates that measuring life events prior to admission, as performed by Ambelas, could be grossly misleading as there will be many illness-related events following the onset of a manic illness.

Paul Sclare Francis Creed

Department of Psychiatry

University of Manchester

Oxford Road

Manchester M139WL

\section{Reference}

BRown, G. W. \& HarRis, T. O. (1978) Social Origins of Depression. London: Tavistock.

\section{Khat-Induced Paranoid Psychosis}

SIR: In February 1984 we reported (Gough \& Cookson, 1984) a case of khat-induced psychosis in a 27-year-old man originally from North Yemen who presented with paranoid delusions and thought broadcasting similar in nature to those described by Critchlow \& Seifert (Journal, February 1987, 150, 247-249). In our patient a urine drug screen at admission was positive for amphetamines but negative for opioids, cannabinoids, cocaine metabolites, and barbiturates. This is to be expected, as khat contains a number of amphetamine-like substances such as d-norpseudoephedrine.

Our patient's family stated that khat is widely used by Yemeni people in Liverpool, fresh supplies being flown in daily. It commonly produces some degree of elation and hyperactivity, but not frank psychotic symptoms. 